\title{
I 9248
}

UCID- 19787

ANALYSIS OF NSWC QUASI-STATIC COMPACTION DATA

FOR POROUS BEDS OF BALL POWDER, MELAMINE, AND

TEFLON, USING STRUCTURAL OOMPACTION MODEL

\author{
A. M. WESTON \\ E. L. LEE
}

Submitted to:

Dr. S. J. Jacobs

Naval Surface Weapons Center

White Oak Laboratory

Silver Spring, Maryland

APRIL 6, 1983

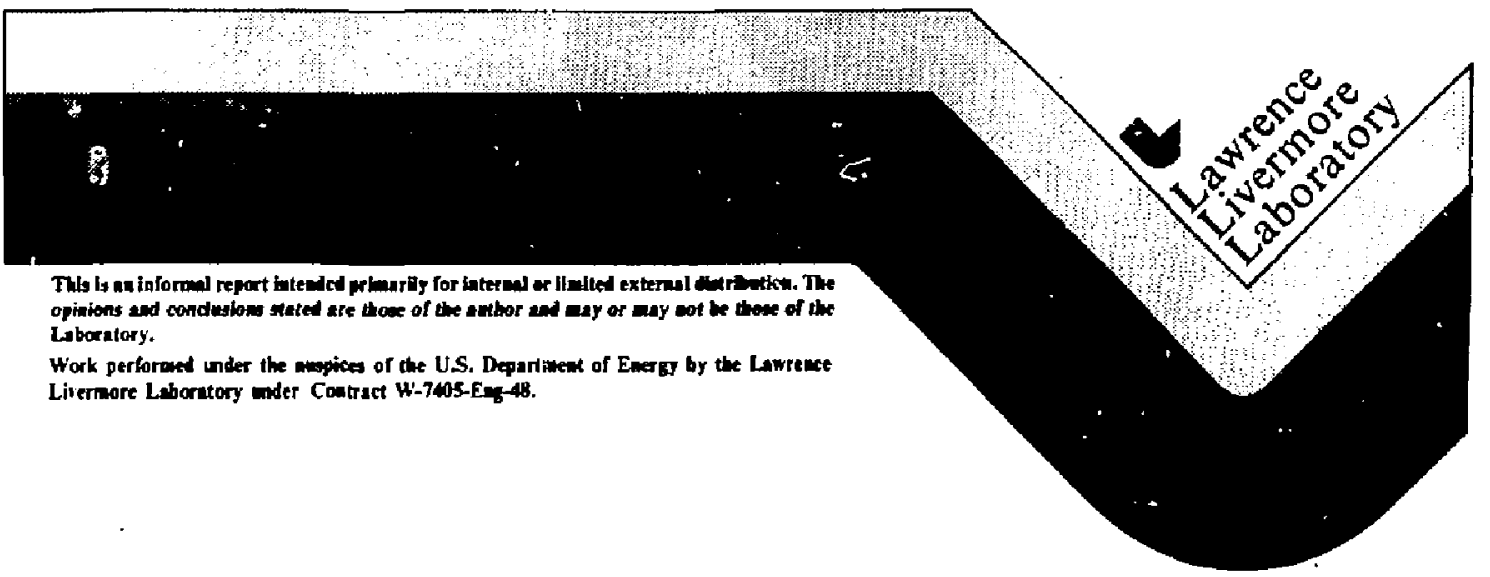


ANALYSIS OV NSWC QUASI-STATIC COMPACTION OATA FOR FOROIIS BEDS OF BALL POWDER, MELANINE, AND TEFLON, USING STRUCTLRAL COMPACTION MOUEL* $\xi$

A. M. Weston

Wm. Brobeck and Associates

E. L. Lee

Lawrence Livermore Nationai Laboratory

University of California

Livermore, California 94550

\section{ABSTRACT}

A "structura]" compaction model is used to correlate NSWC

quasi-static compaction data on porous beds of $\operatorname{six}(6)$ different

inaterials, i.e., four(4) bail powders, melamine, and Teflon. Initial

densities of the porous beds ranged from 44 percent solid "theoretical

maximum density" (TMD) to 70 percent TMD. Maximum compacted densities

were about 90 percent TMD except for Teflon which was compacted to

approximately yo percent TMO. Pressures calculated by the model, plotted

as a function of percent TMD, agree well with the NSWC data.

\section{DISCLAIMER}

This report wes prepared as an aceownt of wort sponsored by an apency of the Unitod Seates GovernmenL. Neither the United States Gomemmeat por any apency thereof, nor any of their

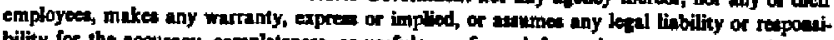

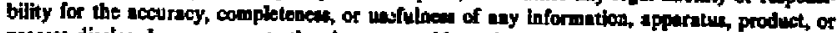
procew dischood, or represents that its use would not infrings privalaly owned rights. Refer-

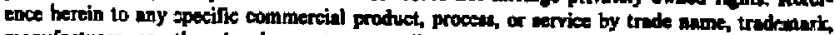

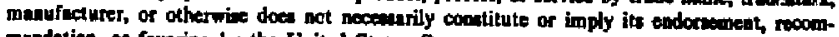
mendation, of favorint by the Unitod States Gowernment of any ayency thereof. The viemand opinions of authont expreand hervin do not abcewerily rinte or refloct those of the United Sutat Government or any arency thereor. 


\section{INTRODUCTION}

The porous material, compaction model is illustrated on Fig. 1. Associated equations are derived in reference 1 . The madel is based upon the collapse of a spherical pore similar to that described by Carroli and Holt. ${ }^{2}$ Radial inertia and strain rate dependance are ignored. It does include trapped gas inside the pore, and a solid material flow stress difference that can de a "strain hardening" function of porosity. This creates both a yield point and a variation in stress witn radius around the pore. Elastic behavior of the porous material is governed by a bulk modulus definition that can fit data from different kinds of materials, from structural foams to compact:ed aggregates of flexible particles.

\section{FORMULATION OF THE MODEL}

The behavior of the model is best explained in relation to relative density, whicn is a function of porosity, $a$, mean solid material density, $\rho$, ano initial mean solid material density, $P_{0}$. Subscript "o" refers to initial conditions

$$
T M D=100 \frac{\rho}{\rho_{0}}\left(\frac{1}{\alpha}\right)
$$

Porosity is defined oy cell dimension $a$, and pore diameter, $d$.

$$
a=\left[1-\frac{\pi}{6}\left(\frac{d}{a}\right)^{3}\right]-1
$$


The cell dimension is related directly to relative dens? and initial relative density.

$$
\begin{aligned}
& a=a_{0}\left[\frac{T M D_{0}}{T D}\right]^{i} ; \text { where, } \\
& i=1 / 3 \text { for cubic compression } \\
& i=1 \text { for } 1 D \text { constant strain compression }
\end{aligned}
$$

The censity of the inatrix material increases slightly with intragranular * compaction pressure. At the low intragranular pressures corresponding to the quasi-static compaction data range here, $p$ dies not increase from its initial value significantly. However, for pore closing pressures when relative density is in excess of 90 percent $\mathrm{MD}$, the increase in $p$ can no longer be ignored.

There are three regimes of compaction behavior, i.e. ', initial elastic, ${ }^{2}$ pore closing $f$ low, ${ }^{3}$ and locked up elastic. In the initial elastic regime, intragranular pressure, $T_{i}$, increases above ambient pressure, Pa, as the porous elastic voltame, $v$, decreases. The increase is deterinined by a bulk modulus that in turn is a function of porosity and pore gas pressure, $\mathrm{Pg}$.

$$
T_{i}=-\int_{v_{0}}^{y} K(a, P g) \frac{d v}{v}+P g
$$

Pore gas pressure is a function of initial and currellt pore diameters and a gas compression process constant $k$.

* The tern "intragranular stress (pressure)" is taken from references 6 and 7 in which the HSWC compaction data is descrihed. It's meaning is the same as, "mean isostatic pressure." 


$$
P g=P a\left(\frac{d_{0}}{d}\right)^{3 k}
$$

To match the quasi-static data $i l$ lustrated here, $k$, the gas compression process constant, was set at the isothermal value of 1,0. This varies froln reference 1 were $k$ was set at a dry air isentropic value of 1.4. The elastic bulk modulus $\mathrm{K}(\alpha, \mathrm{Pg})$, is,

$$
K(\alpha, P g)=\frac{K_{s}}{\alpha} \exp \left(-2 C \frac{a-1}{a}\right)+k P g\left(\frac{a-1}{a}\right)
$$

The solid material bulk modulus, $K_{s}$, increases with pressure. As for solid density at the low pressures corresponding to the quasi-static compaction data, $K_{s}$ does not increase significantly over its initial value. For pore closing pressures when relative density is in excess of 90 percent, the increase in $K_{\mathrm{s}}$ can no longer be ignored. Linear Hugoniot constants for the solid material are used in derived equations that quantify the increase of $k_{s}$ and $p$, with pressure. See reference 1 for details.

The exponential multiplier on $K_{s}$ in equation 6 permits the fitting of the initial elastic behavior for a wide variety of porous materials. Kooker and Anderson ${ }^{3}$ suggested the form of this multiplier based on experimental acoustic data of Elban ${ }^{4}$ and the ceramic compaction data of knudsen. ${ }^{5}$ when the constant, $C=0$, a structural foam is modeled. When the constant, $C>0$, non-linear contact behaviors of discrete particles packed together are modeled. A value of $C=2.2$ will yield results that approximate the Carroll and Holt ${ }^{2}$ model. When $C \gg 0$, elastic pore closure can be approximated. 
When the pressure from equation 4 exceeds a yield value, the pore closing flow regime begins. In this regime, intragranular pressure, $\tau_{j}$, is controlled by a mechanical flow stress equation.

$$
\tau_{i}=P a\left(\frac{d}{d}\right)^{3 k}+x H\left(\frac{d}{a}\right)^{3}\left[\frac{1}{3}\left(\frac{a}{d}\right)^{3}\left(\ln \frac{a}{d}-\frac{1}{3}\right)+\frac{1}{g}\right]+\left(2-\frac{\pi}{3}\right) H \ln \frac{a}{d}
$$

The parameter, $H$, is the difference between radial and tangential pressure in a one dimensional spherical pressure field centered on a pore. Numerically, the value of $H$ is approximated by the flow stess measured in a uniaxial 10 stress compression test on a bar of 100 percent TMD material with a large length to diameter ratio. The results of Hopkinson bar compression experiments yield an approximate mapping of $H$ as a function of strain and strain rate.

Here valuas of $H$ were selected to fit the compaction data. The porous compaction data spans six materials, i.e., from ball powders to melamine, and Teflon. The ball powder data were fitted quite well using a constant value for $H$. The Tefion and melamine data were fitted using a value of $H$ that increases with compactien. This strain hardening Denavior is expressed as,

$$
H=H_{0}\left\{1+B\left[\left(\frac{a}{d}\right)^{N}-1\right]\right\}
$$

Total compaction is the sum of an elastic component and a pore closing flow component. The pore closing flow pressure from equation 7 becomes indefinitely large as the pore dianeter becomes indefinitely 5mal1. Consequently, as solid density is approached, equation 7 no longer controls pressure; instead the pores "lock up" and the compaction behavior is controlled by the bulk compressibility of the solfd material, $K_{s}$. 


\section{COMPARISONS OF CALCULATEO ANO EXPERIMENTAL RESULTS}

The published NSWC data ${ }^{6,7}$ is presented in two fomats, as a semi-log plot of intragranular compaction pressure versus percent TMD, and as a log-log plot of compaction pressure versus the quantity, percent TMD minus initial percent TMD. While the $\log -\log$ plot results in straight line data plots, it masks the essentially elastic-plastic nature of the data. Also, to compare on one graph, different sets of data starting from different values of initial percent TMD, the log-log plots were transformed to the semi-log format with linear percent TMD as the abcissa. figure 2 illustrates the NSWC semi-log data plot for WC 233. Figure 3 illustrates the NSWC $\log -\log$ data plot for WC 140, and also a transfonned semi-log plot.

The computer program that represents the calculation model used here, is programed to plot pressure versus percent TMD in semi-log fomat similar to the first mode of NSWC data presentation. Six points representing NSWC data at different values of percent TMD are plotted and compared to the curve calculated from the model. The NSWC data are numerous. These six "comparison points" are (1) approximately averaged data clusters, or (2) yalues from the NSWC least squares data fit. Figures 4 and 5 illustrates the computer outputs that correspond to Figs. 2 and 3.

Figures 2 through 7 illustrate model results versus NSWC data for four(4) ball powders, HC 231, WC 140, Olin Type A Fluid, and 01 in TS 3660. For these materials the constants $B$ and $N$ in equation (8) are zero; pore closing flow is characterized adequately by a single value for solid material flow stress, $H$. 
Data for winchester ball powder ${ }^{6}$, WC 231 , is first illustrated. These data began at an initial density of 44 percent TMD, a value that is below, but approximately equal to the minimum model density of 47.64 percent 7MD. The model is a cubic array of spherical pores in a matrix of solid material. These pores interfere at less than 47.64 percent TMD when the pore diameter equals the ceil size. At lesser density the model becomes a collection of pieces that do not touch. Except for a small component for bulk gas compression, the model will predict ambient pressure for all densities less than 47.64 percent TMD.

For the entire Dall powder data range, the compaction pressures are sufficiantly low for the solid matrix density, $\rho$, to approximately equal its inital value, $p_{0}$. To jllustrate this the calculated model ine on Fig. 4 includes bulk compressibility while the calculated line on Fig. 2 does not. Similarly the calculated model line on Fig. 5 includes bulk compressibility while the calculated line on Fig. 3 does not.

Figure 8 is a computer code output for $\operatorname{Tef}^{7}{ }^{7}$ (15g, 25g samples) when a constant value for $H$ is used. The data correlation is poor. Figure 9 shows the results when the parameters $B$ and $N$ in equation 7 are allowed to be non-zero, i.e., $H$ increases with cmpaction. The data corralation is much improved. Teflon is mildly "strain hardening."

Figure 10 shows resuits for melamine ${ }^{7}$ ( $15 \mathrm{~g}$ sample) when a constant value for $H$ is used. The data correlation is again poor. Figure 13 is a mlucn improved computer code output when parameters $B$ and $\$$ have very high values, Melamine "strain hardening" is severe. 
In estimating calculation model elastic parameters, the constant $c$ in equation 6 was selected arbitrarity to iit the data. The solid matrix bulk modulus, $K_{s}$, was estimated from shock Hugoniot velocity data. The nitrocellulose ball powder Hugoniot data was assumed to be like pyroxylin from reference 8 . The Teflon Hugoniot data was from reference 9. The Melamine Hugoniot data was assumed to be like TAT from reference 10.

For the six materials cansidered, the elastic and flow parameters used to characterize the compaction behavior are taoulated in Table 1.

\section{DISCLS\$ION}

In correlating the compaction data, the effect of solid matrix compressibility is inportant only for the Teflon data which was compressed to a firlal density of 98 percent TMD. All the remaining data, incluting the Teflon data at less than approximately 90 perrent TMD, can be correlated using constant initial values for solid matrix density, $p=\rho_{g}$, and bulk modulus, $K_{s}=K_{s 0^{\circ}}$. The effect of ignoring compressioility, is illustrated in Fig. 12. The dotted line represents incompressible WC 231. As $p$ approaches $\rho_{0}$ the pressure required to approach 100 percent TMD becomes (incorrectly) large without limit.

Consider a loosily packed parous bed that is loaded, compacts irreversibly to a higher density, and then is unloaded. When reloaded the pressure will first increase with small change in density, i.e., elastically, until the yield limit (represented here by the solid line pore closing flow pressure from equation 7) is reached. With further loading, the solid material will again begin to flow, the pores will 
furtner close, and the density will rupidly increase along the yield limit line. Tnis process is also illustratad in Fig. 12 showing calculated compaction to the yield limit line from various levels of intial compaction.

Figure 13 shows a mapping of yjeld (flow) lines for differing values of matrix flow stress, for materials with solid matrix bulk properties similar to ball powder. The bounding line at the bottom labeled "isothermal pore gas pressure" corresponds to the case where the matrix flow stress is zero. Note now it, and all other yield (flow) lines join a single limit line when at high pressure, the solid matrix density exceeds 100 percent $T M Q$.

Since the compaction model is based upon the notion of pore closing "flow", we attribute compaction data that aligns with softer ball powder materials shown in the Fig. 13 mapping, to a "flow" mechanism. On the other hand, compaction data for melamine, Fig. 10 crosses these curves at a significant angle, indicating that in addition to deforming flow, a strain hardening mechanism is operating. For example, the melamine may be "fracturing", 1.e., making an increased number of smaller particles as it is compacted. 


\section{REFERENCES}

1. A. M. Weston and E. L. Lee, "A Constitutive Model for Porous Materials," Propulsion System Hazards Meeting, Giina Lake, Ca., April 21, 1982, UCRL-B7450.

2. M. M. Carroll, and A. C. Holt, "Static anc Dynamic Pore-Collapsí4 Relations for Ductile Forous Materials," J. Appl. Physics, 43(4), pp. $1626-1636$ (1972).

3. D. E. Kooker, and R. 0. Anderson, "A Mechanism for the Rurning Rate of High Density, Porous, Energetic Materials," 7th Symposium on Detonation.

4. W. L. Elban, NSWC, unpub: ished data, 1960.

5. F, P. Knudsen, "Dependence of Mechanical Strength of arittle, Polycrystallir:a Specimens on Porosity and Grain Size," J. Amer. Ceramic Soc., Vol. 42, No. 8, pp. 376-.387, 1959.

6. NSWC HEPS Technical Progress Report, lanuar: 27, 1982, W. L. Elban, "quasi-Static Compactinn of Porous Bieds," Figs.. 5, 6, 7, 14, and 18, pp. 2-31,

7. H. W. Sanousky, W. L. Eloan, K. Kin, R. R. Bernecker, S. B. Gross, A. R. Clainmont, "Compactiun of Porous Beds of Inert Materials," 7th Detonation Symposium, June 16-19, 1981, pp. 444 and 456, Figs, 8 and 9.

8 Veretennikov, Dremin, Shvejov, "Shock Compressibility of NB Powder in Forous and Un-Porous States," Combustion Explusion and Shock Wares, Vol. 5, No. 4, pp. 342-345, 1969.

9. M. Van Thie1, "Compendium of Shock Have Data," !rRL 50108, 196r, Vol. 3,. Deta for Teflon, 23-9(2-4) -3.

10. M. Van Thie?, "Compendium of Shock Wave Datas" UCRL 50108, 1967, voi. 3,. Cata for TNT, 23-18-2-1(7-3-5-6) - -7. 
JABLE 1 Compaction Hodel Input Paraneters to datch NSWC quasy-static data arrays

\begin{tabular}{|c|c|c|c|c|c|c|c|c|c|}
\hline \multirow[b]{2}{*}{ Material } & \multirow[b]{2}{*}{ MD } & \multicolumn{4}{|c|}{ Elastic Regi-e } & \multicolumn{3}{|c|}{ Flow Regine } & \multirow{2}{*}{$\begin{array}{l}\text { Hean } \\
\text { Particle } \\
\text { Ofa. }\end{array}$} \\
\hline & & Po & $c$ & $s$ & C & $H_{0}$ & 8 & $n$ & \\
\hline & - & g/ce & $\pi / t ;$ & $=$ & - & $6 P a$ & & & 4ा \\
\hline WC231 & 47.65 & 1.63 & 1.7 & 1.85 & 3.5 & 0.060 & 0. & 0. & .7874 \\
\hline$W C 140$ & 57.8 & 1.63 & 1.7 & 1.85 & 3.5 & 0.165 & 0. & 0. & .4115 \\
\hline orin ype A & $80.0^{\circ}$ & 3.63 & 1.7 & 1.85 & 4.5 & 0.130 & 0. & 0. & .045 \\
\hline TS3660 & 55.2 & 1.63 & 1.7 & 1.85 & 4.0 & 0.108 & 0. & 0. & .7137 \\
\hline Tefion $7 C$ & $66.0^{*}$ & 2.305 & 1.88 & 2.07 & 5.0 & 0.0089 & 1.0 & 0.75 & 2.055 \\
\hline Melumine & $69.5 * *$ & 1.543 & 2.66 & $i .826$ & 5.0 & 0.0078 & 3.2 & 4.0 & .055 \\
\hline
\end{tabular}

$=\quad K S U C$ sidted an initial density of bu.2 percent TMD, reference 5.

* Estimated from HSwC data plots, reference $?$. 
PORE DIA., d, GAS FILLED
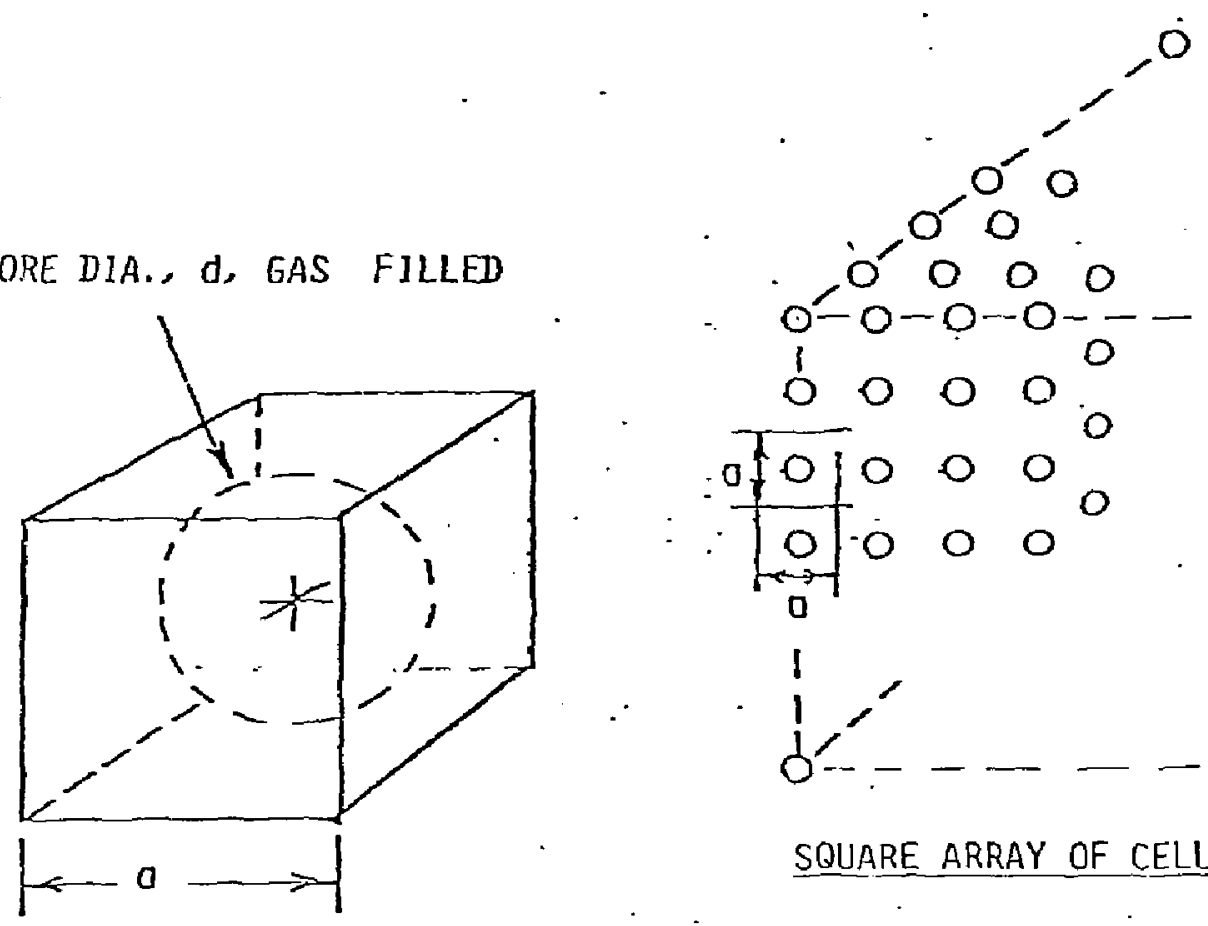

\section{COMPACTION CELL.}

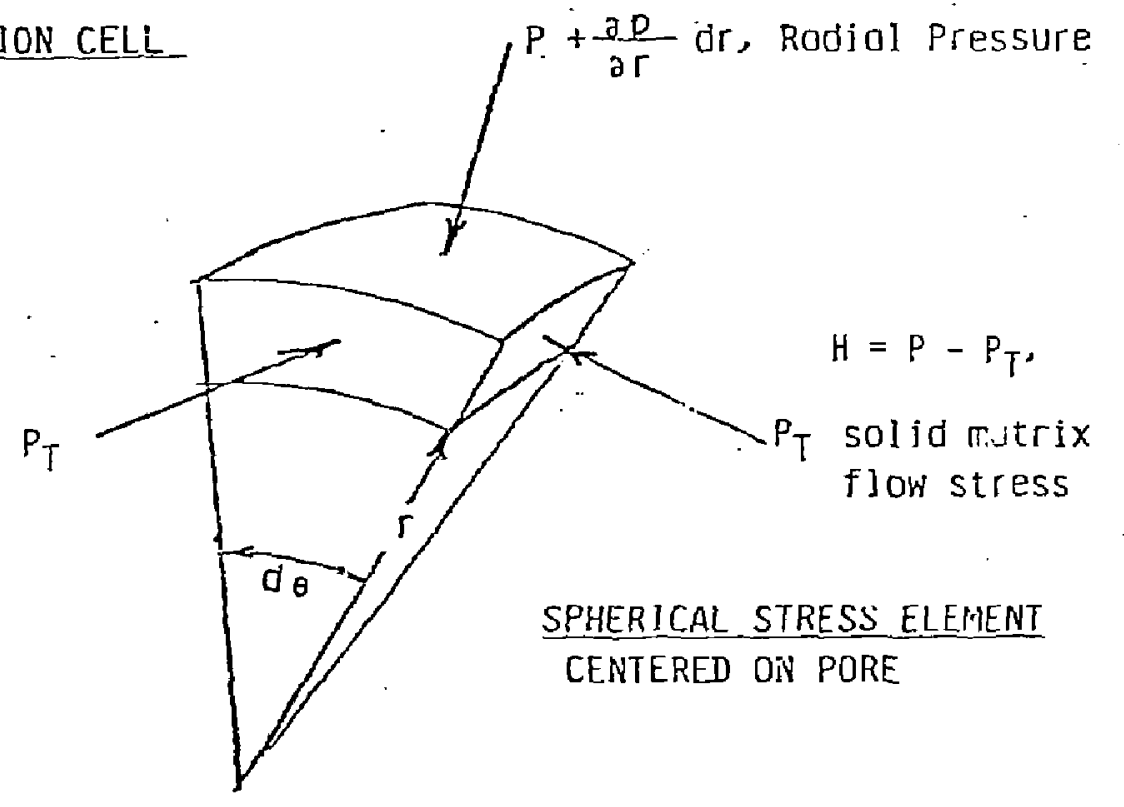

FIG. 1 


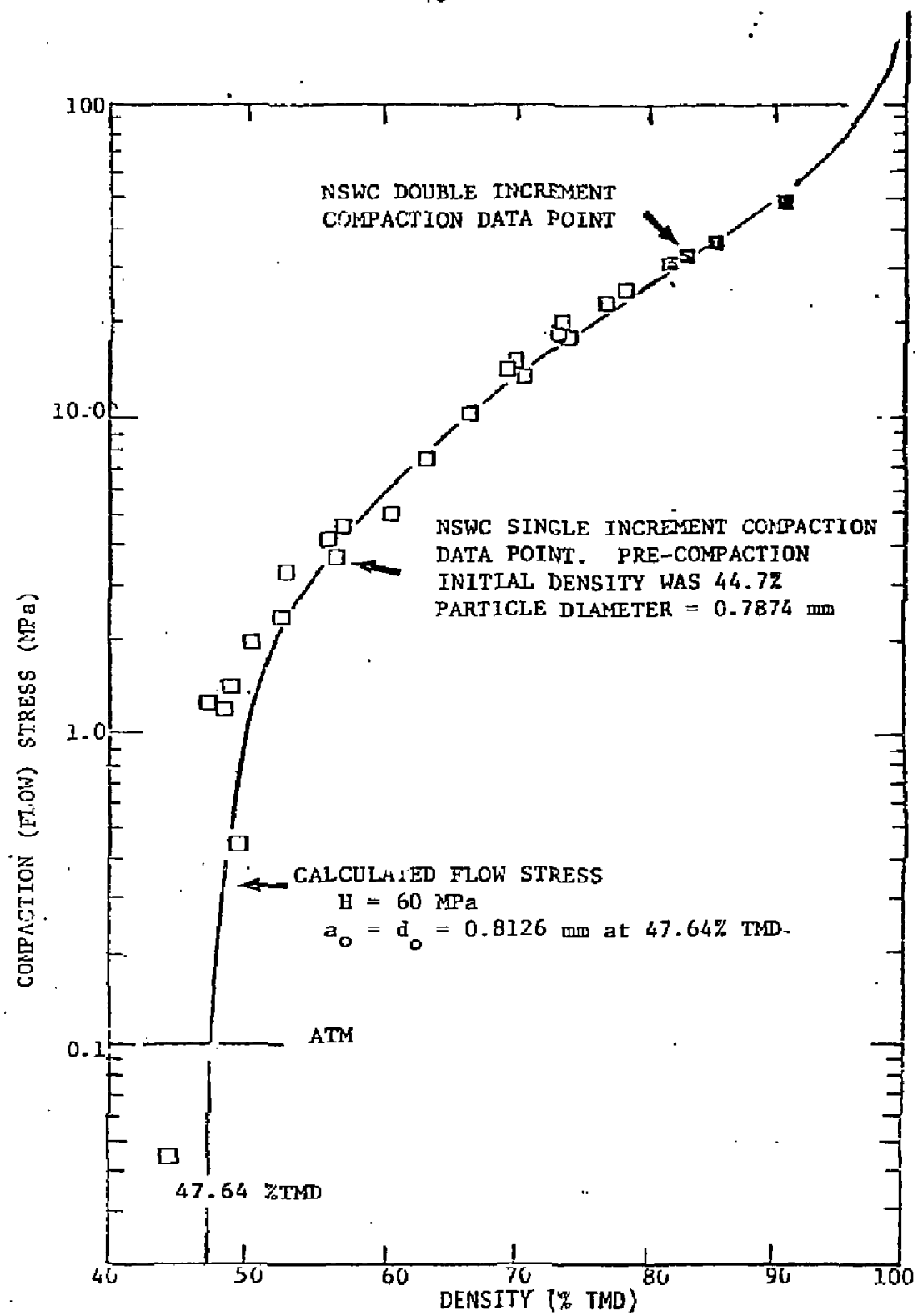

Fiz. 2 Aralytical mechanical flow stress and NSWC intergranular stress data versus density for $12 \mathrm{~g}$ Winchester 231 ball powder. 


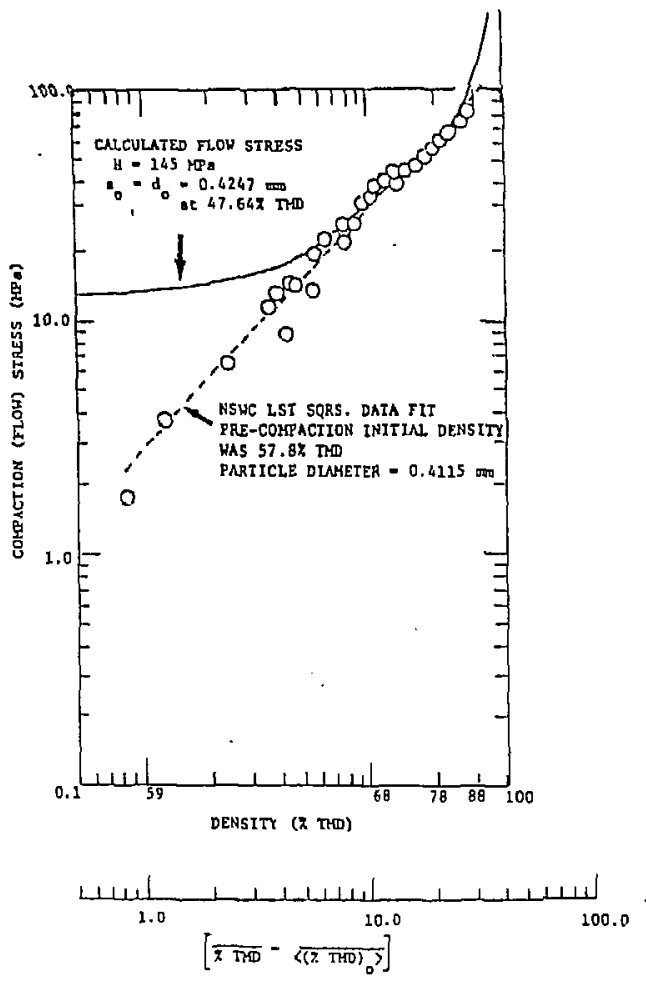

Fig. 3 a nnolytical mechanical flow stress and N5HC intragranular stress data versus density for $15 \mathrm{~g}$ Olf: HCIAO ball powder.

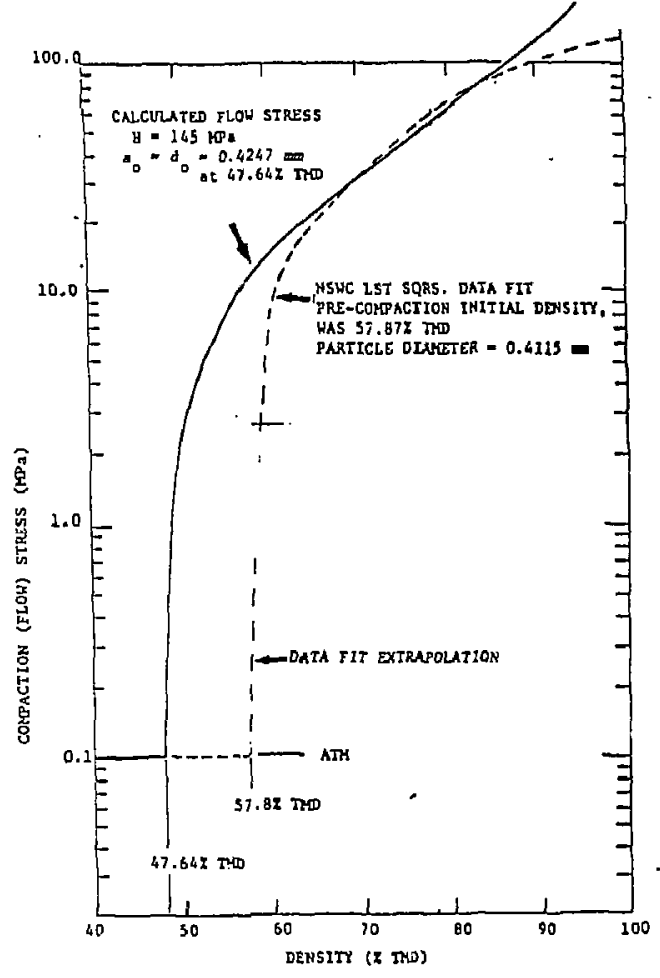

Fig. 3 b Analytical mechanical flow stress and NrHC LST sqrs. Intragranular stres s daca fit versus dens iey far 15 olin hicla ball powóer. 
$-15=$

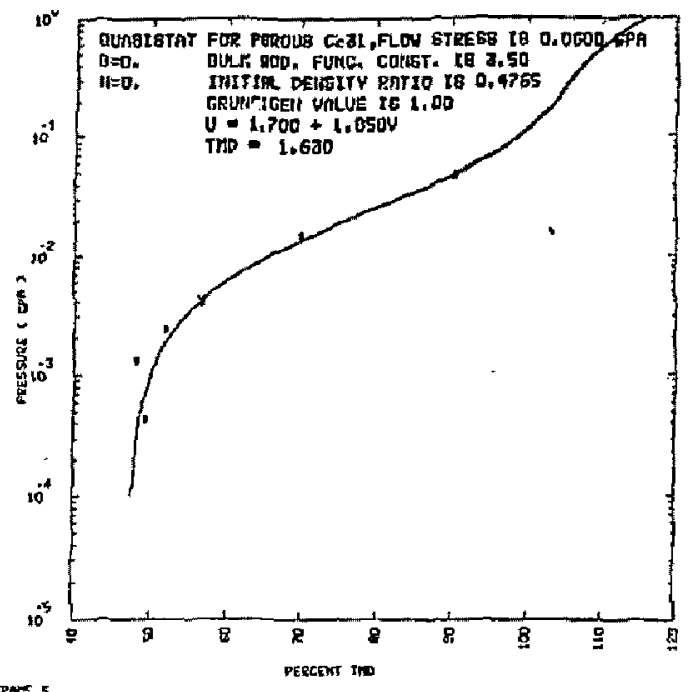

Fig. 4

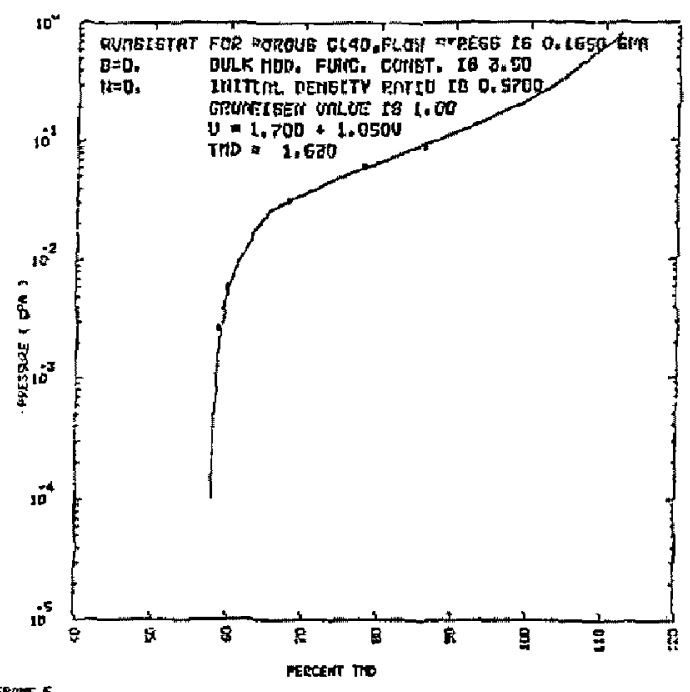

Ferre 5

FIg. 5 


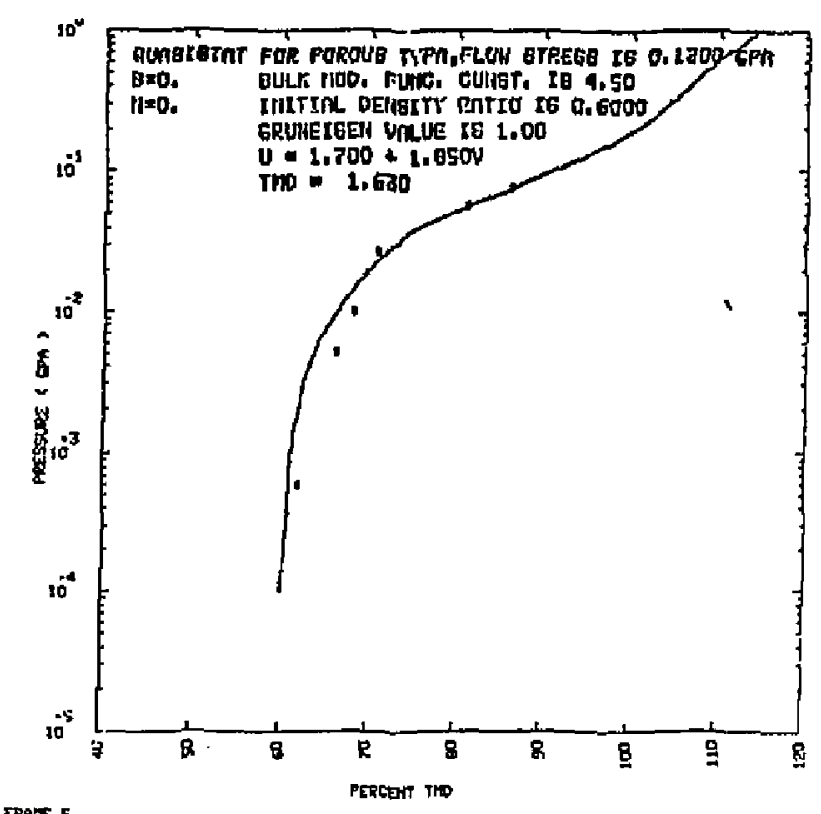

Tranes

Fig. 6

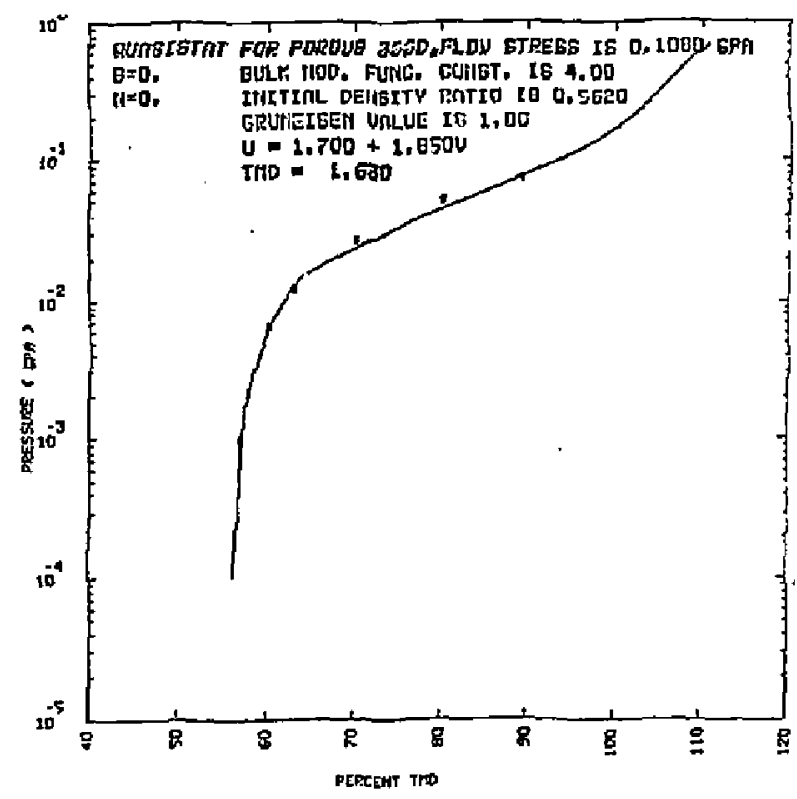

FRMAE 5

Fig. 7 


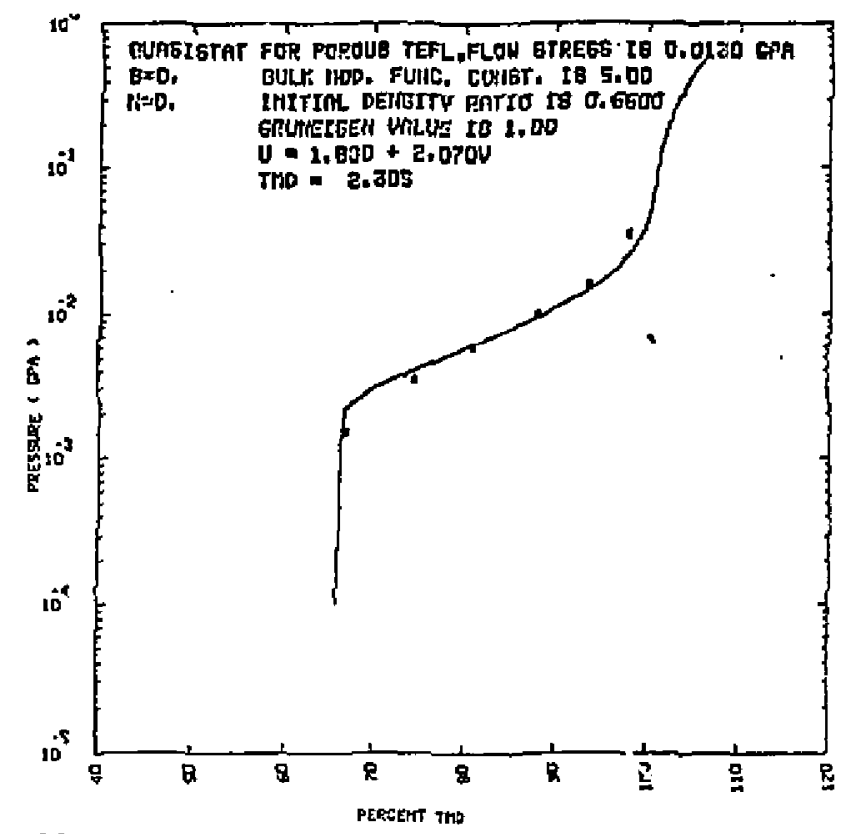

FDARE :

Fig. 3

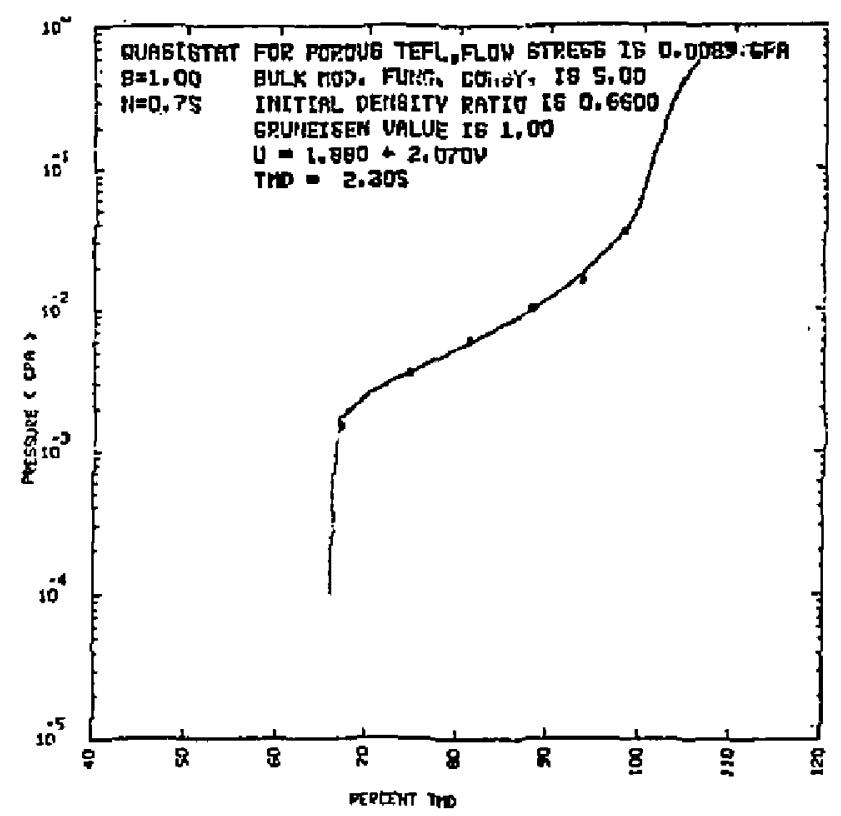

rente 5

Fig. 9 


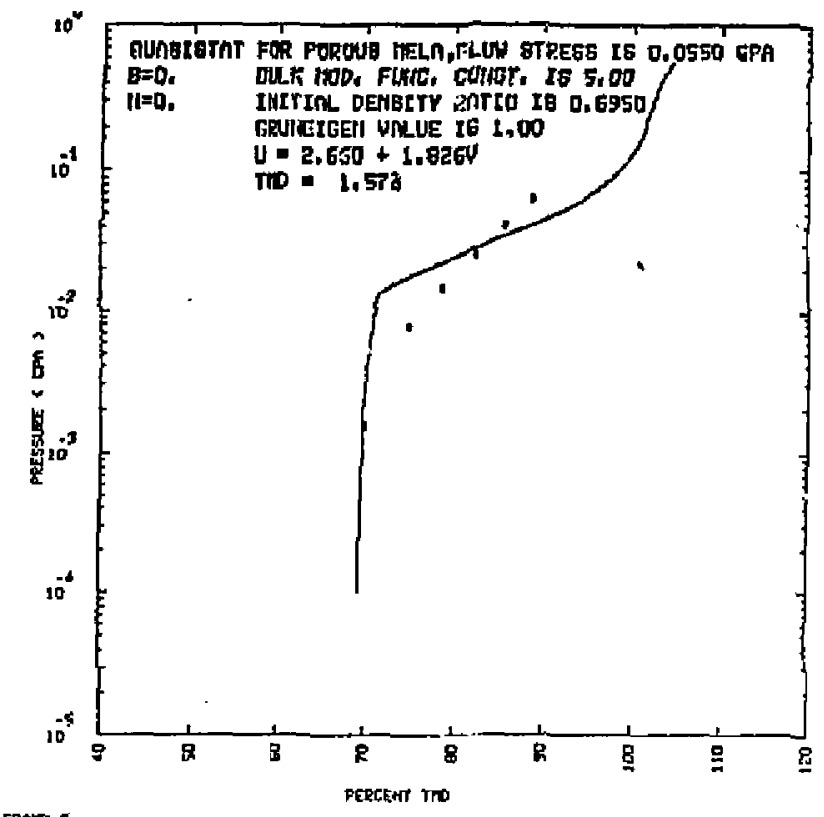

FROHE

Fig. 10

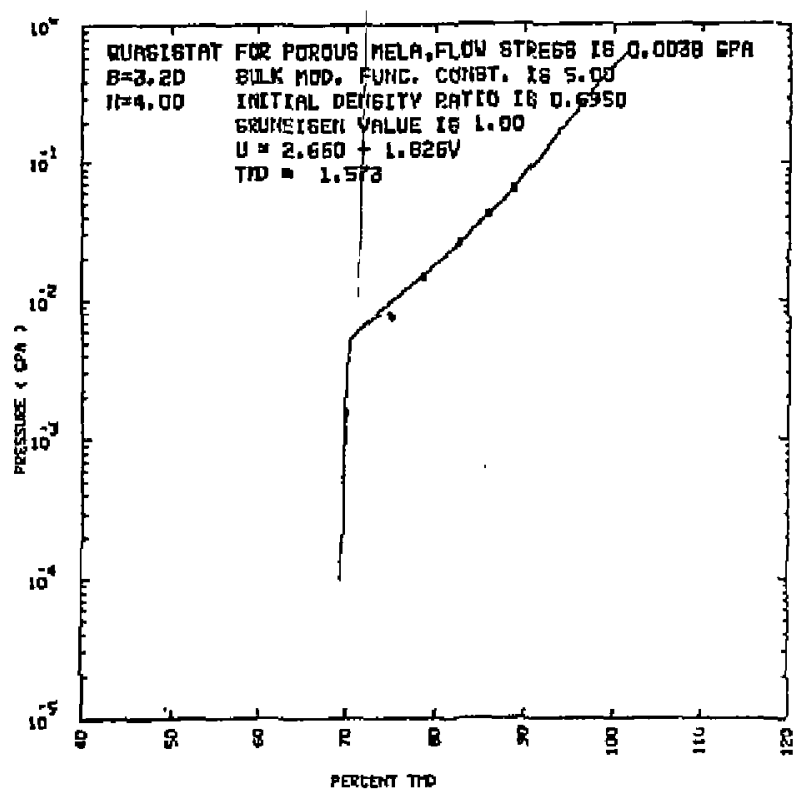

FRrTE 5

Fig. 11 


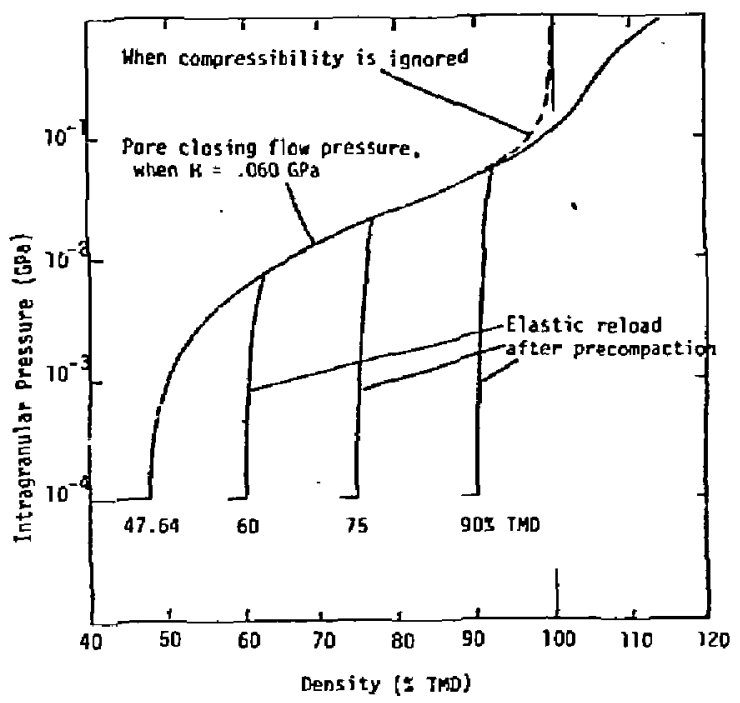

Fig. 12 Pare closing flow pressure versus density for W[231, illustratim the effects of compressibility and precompaction.

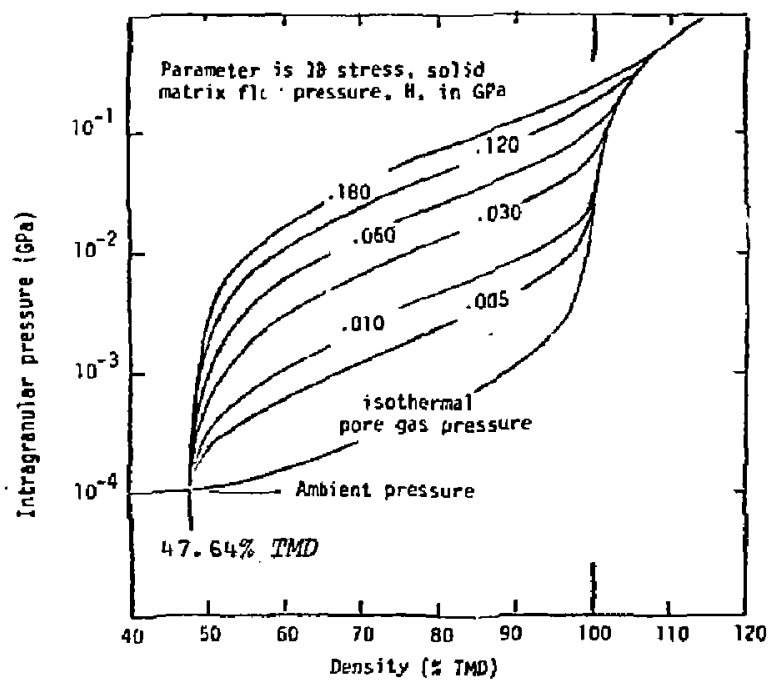

Fig. 13 pare closing flow pressure versus density and solid matrix flow pressure, for ball powder type materials. 